\title{
A CLASSE VERBO EM OFAYÉ: ASPECTOS SINTÁTICOS
}

\section{Maria das Dores de Oliveira*}

Resumo: Neste artigo, propomo-nos a descrever alguns aspectos da estrutura sintática de verbos em Ofayé, basicamente os tipos principais de verbos encontrados na língua e a ordem dos constituintes na sentença. Ofayé é uma língua indígena brasileira, considerada pertencer ao tronco lingüístico Macro-Jê. Essa língua é falada pelos Ofayé, localizados no município de Brasilândia, Estado de Mato Grosso do Sul.

Palavias-chave: Sintaxe. Verbo. Ofayé. Língua indígena.

\section{Classes de verbos}

Os verbos em Ofayé podem ser divididos em três classes principais: ativos, incluindo verbos transitivos primários e a maior parte dos verbos intransitivos que são ações - considerando-se, evidentemente, a prototipicalidade ou a neutralização de papéis semânticos sob uma função sintática, no caso do Ofayé, o Sujeito; estativos, incluindo nessa classe os verbos adjetivais, estativos propriamente falando, e os verbos que codificam funções corporais; e verbos de emoção, não necessariamente incluídos em uma terminologia típica.

Na estrutura gramatical do Ofayé, três papéis semânticos parecem ser relevantes: o Agente, o Paciente e o Recipiente. De acordo com Payne (1997, p. 133), tem-se observado empiricamente que há uma tendência das línguas a ter cerca de três categorias distintas de relações gramaticais centrais,

Professora da FUNAI/IFP, doutora em Linguiística pela Universidade Federal de Alagoas (UFAL) 
geralmente, sujeito, objeto e objeto indireto. Embora em Ofayé não existam muitas pistas que permitam identificar essas relações, vamos aqui, para efeito de descrição, considerar essas três funções gramaticais, observando os tipos de estrutura sintática apresentados pelas classes de verbos.

\section{Verbos ativos}

\subsection{Intransitivos}

Um verbo intransitivo típico, aqui usado como exemplo, é o verbo dançar. Podemos dizer que ele é um verbo intransitivo típico porque expressa uma ação-processo com apenas um participante, o Ator ${ }^{1}$. Para que uma sentença seja gramatical, em Ofayé, é bastante que o verbo esteja acompanhado por um elemento pronominal que desempenha as funções sintáticas e representa os papéis semânticos correspondentes. Que esses elementos são formas livres e não prefixos, podemos ver quando, sendo o sujeito de terceira pessoa explicitado por um nominal, esse nominal pode ser inserido entre o elemento pronominal e o verbo.

1) $\left[\right.$ õtə ə $\left.\int \mathrm{jow} \mathrm{je}\right]$

ôta a fow Se

3SUJ homem dançar

o homem dança/dançou

Usaremos Ator aqui como um termo cover para os tipos de participantes que podem aparecer nessa posição, desde Agentes até Temas e outros tipos. 
A seguir, apresentamos a conjugação de um verbo intransitivo.

\begin{tabular}{|c|c|c|c|c|}
\hline \multicolumn{2}{|c|}{ NÚMERO/PESSOA } & SUJEITO & VERBO & \\
\hline \multirow{3}{*}{ Singular } & 1 & ta & Se & eu danço/dancei \\
\hline & 2 & te & $\int \mathrm{e}$ & tu danças/dançaste \\
\hline & 3 & õta & Se & ele dança/dançou \\
\hline \multirow{3}{*}{ Plural } & 1 & ta & 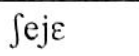 & nós dançamos \\
\hline & 2 & te & Јej $\varepsilon$ & vós dançais/dançastes \\
\hline & 3 & õta & 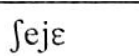 & eles dançam/dançaram \\
\hline
\end{tabular}

Quadro 1: Conjugação de um verbo intransitivo

Na estrutura com verbo intransitivo, o Agente é representado pelos pronominais, /ta/, /te/ e /õta/ - primeira, segunda e terceira pessoas, respectivamente.

\subsection{Transitivos}

Os verbos transitivos - verbos de ação-processo com dois participantes, um Agente e um Paciente - têm uma estrutura sintática com argumentos que, quando expressos pronominalmente, apresentam-se do seguinte modo:

\begin{tabular}{|l|c|l|l|l|l|}
\hline \multicolumn{2}{|l|}{ NÚMERO/PESSOA } & SUJEITO & OBJETO & VERBO & \\
\hline \multirow{4}{*}{ SINGULAR } & 1 & ta & wa & gi & eu vejo/vi algo \\
\cline { 2 - 6 } & 2 & te & e & gi & tu vês/viste algo \\
\cline { 2 - 6 } & 3 & õta & ã & gi & ele vêlviu algo \\
\hline \multirow{4}{*}{ PLURAL } & 1 & ta & aka & gi & nós vemos/vimos algo \\
\cline { 2 - 6 } & 2 & te & eke & gi & vós vedes/vistes algo \\
\cline { 2 - 6 } & 3 & õta & ida & gi & eles vêm/viram algo \\
\hline
\end{tabular}

Quadro 2: Conjugação de um verbo transitivo 
Exemplos da construção transitiva são apresentados a seguir. Ilustramos, com os exemplos de (2) a (5) a construção gramatical com todos os argumentos representados apenas pronominalmente.

2) [ta ã ki $]$

ta hã gi

1SUJ 3OBJ ver

eu o vejo/vi

3) [ōtə wa ki]

õto wa gi

3SUJ 1OBJ ver

ele me vê/viu

4) [ta e kãj]

ta e kãj

1SUJ 2OBJ matar

eu te mato/matei

5) [õtə wa kati $]$

õtə wa kati

3SUJ 1OBJ bater

ele me bateu

Nessas construções, [ta], [te] e [ õtə] são Agentes, enquanto que [wa], [e] e [hã] são pacientes. A ordem canônica é, assim, definida como sendo SOV. Esses índices pronominais que referem a Agente e 
Paciente na sentença transitiva são também índices gramaticais sem referência externa. Quando nominais, que possuem referência plena, aparecem na sentença, os índices gramaticais permanecem, o que nos permite dizer que eles também são correferenciadores. $O$ índice de Paciente, entretanto, pode ser omitido, caso esse argumento seja expresso por um nominal. O índice de sujeito é, canonicamente, obrigatório ${ }^{2}$. A ordem dos nominais na sentença não parece ser rigorosa, mas o nominal representando um paciente, de modo geral ocupa a segunda posição, depois do sujeito e antes do verbo, na sentença central. Entretanto, esse nominal com função objeto pode ainda vir depois do verbo ou depois do Recipiente representado nominalmente e correferenciado na sentença por um pronome. Em uma secção específica, chamada de ordem dos constituintes na sentença, apresentamos todas as ordens possíveis desses argumentos centrais.

\subsection{Bitransitivos}

Verbos bitransitivos, cujo protótipo é o verbo dar - com uma estrutura semântica que apresenta três argumentos, Agente, Paciente e Recipiente - comportam-se sintaticamente do seguinte modo:

- o Agente, o doador, é expresso por um pronome da série sujeito;

- o Paciente, o objeto doado, é expresso por um pronome da série objeto;

- o Recipiente, o participante a quem o objeto é doado, é expresso por um pronome da série objeto, com ligeira modificação, marcado com a posposição [he]. É, portanto, um Dativo, em termos de marcação de caso, mesmo se a marcação é sintática em Ofayé.

Evidentemente, essa obrigatoriedade diz respeito ao nível da sentença. No discurso fluente, espontâneo, como em qualquer língua, mesmo naquelas que são consideradas no modo de falar gerativista de pró-drop, o sujeito de uma sentença pode ser elidido, desde que ele pode ser recuperado do contexto. 
Nessa estrutura bitransitiva, há um jogo interessante entre os participantes.

A princípio, toda a estrutura gramatical pode ser expressa apenas pelos índices actanciais, Sujeito -Objeto 1 - Objeto 2 - Verbo ${ }^{3}$.

6) [te wa he nõe]

te wa he nãw-ge

2SUJ 1OBJ DAT dar-VER

tu me destes (alguma coisa)

7) [ta e he nõe]

ta $\mathrm{e}$ he nãw-ge

1SUJ 2OBJ DAT dar-VER

eu te dei (alguma coisa)

Se o sujeito for de primeira pessoa e o recipiente de segunda pessoa (8) ou vice-versa (9), tanto o sujeito quanto o objeto indireto estarão explicitados, gramaticalmente. O objeto será sempre de terceira pessoa e, por isso, equivalente a [ø], a menos que seja expresso apenas pronominalmente.

8) [ta e he nõ krigete]

ta $\mathrm{e}$ he nãw garigete

3SUJ 2OBJ1 DAT dar ovo.de.galinha

eu te dei o ovo 
9) [te wa he nõ krigete]

te wa he nãw garigete

2SUJ 1OBJ1 DAT dar ovo.de.galinha

tu me deste o ovo

Nos dois exemplos, poderíamos postular um morfema [ø] para a posição do objeto antes do verbo. Esse pronome correferenciaria ao nome [krigete] ovo, que segue o verbo. Não assumiremos, porém, neste trabalho, essa posição e continuaremos a transcrever os exemplos como vimos fazendo até aqui.

O sujeito de terceira pessoa é omitido, se o recipiente é de outra pessoa gramatical - primeira ou segunda. Em (10) e em (11), o sujeito é de terceira pessoa - ele - e não tem realização fonética na estrutura gramatical, onde encontramos apenas o argumento Recipiente, representado por um pronome gramatical objeto marcado como Dativo.

10) [wa he nõ krigete]

$\varnothing$ wa he nãw garigete

3SUJ 1OBJ DAT dar ovo.de.galinha

ele me deu o ono

11) [e he nõ krigete]

$\varnothing$ e he nãw garigete

3SUJ 2OBJ DAT dar ovo.de.galinha

ele te deu o ovo

Se o sujeito for de pessoa diferente da terceira e o recipiente de terceira pessoa, o pronome que refere ao recipiente pode ser 
omitido. Em (12), o sujeito é [ta], primeira pessoa e o recipiente, terceira pessoa, não se realiza foneticamente, sendo representado por [ø]. O fato se observa ainda em (13), com sujeito de segunda pessoa [te] e recipiente de terceira pessoa [ø].

12) [ta he nõ krigete]

ta $\varnothing$ he nãw garigete

1SUJ 3OBJ DAT dar ovo.de.galinha

eu lhe dei o ovo

13) [te he nõ krigete]

te $\varnothing$ he nãw garigete

2SUJ 3OBJ DAT dar ovo.de.galinha

você lhe deu o ovo

Se o recipiente for expresso por um sintagma nominal, ainda assim, a estrutura sintática será mantida, com o recipiente [ø], seguido da posposição que marca Dativo. Depois do verbo, vem o sintagma nominal, que pode ser ou não marcado como Dativo. Em (14), o nome próprio [tegĩ] Tegin, que ocorre depois do verbo é o Recipiente, marcado como Dativo, seguido do nome [krigete] ovo, que é o objeto direto.

14) [ta he nõ tegi he krigete]

ta $\varnothing$ he nãw tegi he garigete

1SUJ 3OBJ DAT dar Tegin DAT ovo.de.galinha

eu dei o ovo a Tegin 
Essa estrutura parece dar a seguinte informação: eu dei algo a alguém, que, por si só, é gramatical na língua. Agora, precisando dar uma informação em termos referenciais e não apenas gramaticais, dos participantes, acrescentam-se Nome marcado como Dativo, representando o Recipiente, e Nome não marcado, representando o Objeto. Os nominais refletem-se do lado oposto do verbo, como em um espelho.

Se o sujeito for expresso por um nome, o pronome correferenciador de terceira pessoa, exigido pela estrutura sintática, volta a aparecer. A marca de Dativo, nesse caso, está sobre um morfema [ø], pois os dois participantes, Agente e Recipiente, sāo da mesma pessoa gramatical.

15) [Maria õta he nõ krigete]

Maria õta $\varnothing$ he nãw garigete

Maria 3SUJ 3OBJ DAT dar ovo.de.galinha

Maria deu o ovo a ela

O Recipiente, nesse caso, é expresso apenas pronominalmente na estrutura gramatical. Não há um nome ao qual ele correferenciaria e que viria depois do verbo.

Se compararmos os dois exemplos abaixo, teremos uma visão mais clara dos fatos.

16) [Maria õta he nõ krigete]

17) _ õtə ø he nãw garigete 3SUJ 3OBJ DAT dar ovo-de-galinha

16') Maria ela the deu o ovo-de-galinha

17") ___ ela the deu o ovo-de-galinha 
Dessa análise, um quadro sinótico dos pronomes que representam as principais relações gramaticais em Ofayé, considerando apenas os verbos Ativos, pode ser esboçado.

\begin{tabular}{|c|l|l|l|}
\hline PESSOA & SUJEITO & OBJETO INDIRETO & OBJETO DIRETO \\
\hline 1 & ta & wa he & wa \\
\hline 2 & te & e he & e \\
\hline 3 & ota & $ø$ he & ã \\
\hline
\end{tabular}

Quadro 3: Pronomes que desempenham funções sintáticas centrais

O Quadro a seguir mostra o jogo de pessoas gramaticais na estrutura bitransitiva, basicamente entre os participantes com papel semântico Agente e Recipiente.

\begin{tabular}{|c|l|l|l|l|}
\hline \multirow{2}{*}{ Recipiente } & \multicolumn{2}{c|}{2} & \multicolumn{2}{c|}{3} \\
\hline & ta & te & ott \\
\hline 1 & - & wa he & - & wa he \\
\hline 2 & e he & - & - & e he \\
\hline 3 & ø he & ø he & ø he & - \\
\hline
\end{tabular}

Quadro 4: Jogo das pessoas gramaticais na estrutura bitransitiva

Um verbo que tem o mesmo comportamento sintático que o verbo dar é mostrar, como ilustram os exemplos (18) e (19).

18) [ok ${ }^{w}$ ie õto he õg ${ }^{w}$ e hokojfwara hitaje]

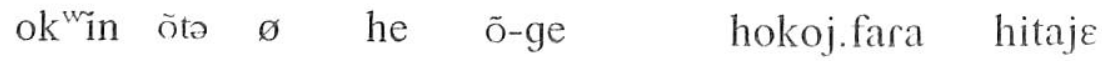
Joana 3SUJ 3OBJ DAT mostrar-VER tamanduá.pé anta Joana mostrou a anta a Pé-de-Tamanduá (Ramona) 
A marcação do nominal Recipiente, depois do verbo, como Dativo, não é obrigatória, dado que o nominal Agente já ocupa a primeira posição na sentença, antes do verbo, ao passo que o nominal Tema (Objeto), desde que não é marcado, ocupa a última posição na sentença.

19) [ta e he õg ${ }^{\text {we e hitaje] }}$

ta e he ō-ge hitaje

1SUJ 2OBJ DAT mostrar-VER anta

eu mostrei a anta a você

\subsection{Verbos estativos}

Há dois tipos de verbos que podem ser ditos verbos estativos. São os verbos que compõem predicados adjetivais e os verbos que expressam funções corporais involuntárias. Os pronomes que têm função gramatical e/ou correferencial nessa estrutura sintática são diferentes dos pronomes com essas funções na estrutura dos verbos transitivos primários e dos demais verbos intransitivos.

2.4.1 Predicados adjetivais

\begin{tabular}{|l|c|l|l|l|}
\hline \multicolumn{2}{|l|}{ NÚMERO/PESSOA } & SUJEITO & VERBO & \\
\hline \multirow{4}{*}{ SINGULAR } & 1 & fo- & grej & eu sou bom \\
\cline { 2 - 5 } & 2 & $\mathrm{e}-$ & grej & tu és bom \\
\cline { 2 - 5 } & 3 & hã- & grej & elé é bom \\
\hline \multirow{4}{*}{ PLURAL } & 1 & aka- & krej & nós somos bons \\
\cline { 2 - 5 } & 2 & eke- & krej & vocês são bons \\
\cline { 2 - 5 } & 3 & ida- & krej & eles são bons \\
\hline
\end{tabular}

Quadro 5: Conjugação de um predicado adjetival 
2.4.2 Funções corporais

\begin{tabular}{|c|c|c|c|c|}
\hline \multicolumn{2}{|c|}{ NÚMERO/PESSOA } & SUJEITO & VERBO & \\
\hline SINGULAR & 1 & $\int \partial-$ & $\int \varepsilon h e ̃ n$ & cu sangro \\
\hline & 2 & e- & đEhẽn & tu sangras \\
\hline & 3 & hã- & 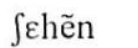 & ole sangra \\
\hline PLURAL & 1 & aga- & SEhẽn & nós sangramos \\
\hline & 2 & ege- & $\int \varepsilon h e ̃ n$ & vocês sangram \\
\hline & 3 & ida- & ¿Ehẽn & eles sangram \\
\hline
\end{tabular}

Quadro 6: Conjugação de um verbo de funções corporais

Desse modo, podemos ver que a estrutura sintática nas classes de verbos que se configuram como estativas é diferente da estrutura sintática encontrada para as classes de verbos que se configuram como ativas. Nesta classe, o pronome de primeira pessoa não é igual nem ao sujeito, nem ao objeto dos verbos transitivos primários, mas um elemento diferente. Os pronomes que constituem a estrutura gramatical dos verbos estativos não podem ser repetidos, como ocorre com os pronomes da classe ativa, para as pessoas do plural. Com os verbos estativos, tem-se que usar para o plural os pronomes livres ${ }^{4}$.

\subsection{Verbos de emoção}

Os verbos que expressam emoção em Ofayé apresentam uma estrutura sintática específica. O experienciador é semanticamente um Recipiente e, como tal, é marcado como Dativo, constituindo-se um Objeto Indireto do ponto de vista sintático. O objeto da emoção é semanticamente um estímulo e tratado como Objeto, na estrutura sintática.

4 Os pronomes de plural, com exceçāo de /ida/, também foram encontrados em fala espontânea com verbos da estrutura ativa. Em dados elicitados, porém, esses pronomes nunca são utilizados nessa estrutura. 


\begin{tabular}{|c|c|c|c|c|c|}
\hline \multicolumn{2}{|c|}{ NÚM/PES } & SUJ & VERBO & OBJ & \\
\hline \multirow[t]{3}{*}{ SG } & 1 & wa he & Sefi & {$\left[\int \partial g i j \tilde{e}\right]$} & en gosto do meu marido \\
\hline & 2 & e he & Sefi & [a gijẽ ] & Iu gostas do teu marido \\
\hline & 3 & hã he & Sefi & [ãgijẽ] & ela gosta do marido dela \\
\hline \multirow[t]{3}{*}{ PL } & 1 & aka he & Sefi & [akijẽne] & nós gostamos dos nossos maridos \\
\hline & 2 & eke he & Sefi & [ekijẽne] & vocês gostam dos maridos de vocês \\
\hline & 3 & ida he & Sefi & [te gijẽñ] & elas gostam dos maridos delas \\
\hline
\end{tabular}

Quadro 7: Conjugação de um verbo de emoção

Segundo Van Valin (2001, p. 27), "expressing experiencer arguments in the dative case is not a property of so-called 'exotic' languages alone; it also happens in many Indo-European languages", e cita como exemplos Espanhol, Alemão e Croata.

\section{Definindo a estrutura sintática de Ofayé}

Considerando apenas as duas classes principais, verbos transitivos primários e verbos intransitivos, temos a seguinte configuração:

a) os verbos transitivos primários são verbos de ação prototípicos e comportam-se como tal, com o Agente sendo tratado sintaticamente como Sujeito;

b) uma parte dos verbos intransitivos comporta-se sintaticamente do mesmo modo que os verbos transitivos, ou seja, seu argumento único é tratado como o Agente, nas sentenças com verbos transitivos primários. Assim, $\mathrm{A}=\mathrm{S}$. De quinze classes semânticas levantadas, onze comportam-se, sintaticamente, do mesmo modo que os verbos transitivos primários.

c) Outra parte dos verbos intransitivos, incluindo-se aí, grosso modo, os predicados adjetivais, recebem uma marcação de sujeito diferente. 
Por esse cenário, teríamos uma estrutura sintática do tipo que é definido na literatura como Ativa-estativa. Contudo, algumas complicações aparecem, como veremos a seguir.

Os verbos estativos - predicados adjetivais e funçōes corporais - tomam como argumento único um sujeito que não é agentivo. Embora, nas segunda e terceira pessoas do singular, esse argumento seja igual ao objeto dos verbos transitivos primários, o fato de o pronome utilizado com esses verbos ser diferente, na primeira pessoa, do objeto dos verbos transitivos primários nāo nos permite dizer que o sujeito dessa classe de verbos é tratado como o objeto dos verbos transitivos primários, o que configuraria a língua como sendo do tipo sintático ativo-estativo.

Em vez disso, o que ocorre é que esse sujeito é diferente de A, mas é também diferente de $\mathrm{S}$ e de $\mathrm{O}$. Para efeito de descrição, chamaremos o sujeito desses verbos Internalizado ou Inerente. Por isso, a situação em que se encaixa a estrutura sintática da língua Ofayé parece mais próxima de um tipo que apresenta intransitividade cindida, porém com o argumento único dos verbos estativos sendo diferente do argumento Paciente dos verbos transitivos primários.

\begin{tabular}{|c|l|l|}
\hline A & sujeito de verbos transitivos primários & \multirow{2}{*}{ Agente } \\
\cline { 1 - 2 } S & sujeito de verbos intransitivos & \\
\hline O & objeto de verbos transitivos & Paciente \\
\hline I & sujeito de verbos estativos & Internalizado \\
\hline
\end{tabular}

Quadro 8: Correlação entre sujeito, objeto e classes de verbos

Finalmente, há uma classe de verbos, os que expressam emoções, que apresentam uma estrutura sintática diferente. Esses verbos têm dois argumentos na estrutura sintática, semanticamente um Experienciador da emoção e um Estímulo, o alvo da emoção. O Experienciador é tratado como Recipiente, desde que marcado como 
Dativo, e o Estímulo como Paciente. Essa última classe pode ser desconsiderada no estabelecimento da estrutura sintática, desde que todas as línguas parecem ter verbos que se comportam à margem do padrão predominante 5 .

Podemos, então, modificar o quadro acima, para acrescentar um quinto tipo de participante e dar uma visão geral da configuração sintática da língua, no que pudemos até aqui observar.

\begin{tabular}{|c|l|l|}
\hline A & sujeito de verbos transitivos primários & \multirow{2}{*}{ Agente } \\
\hline S & sujeito de verbos intransitivos & \\
\hline O & objeto de verbos transitivos & Paciente \\
\hline I & sujeito de verbos estativos & Internalizado \\
\hline R & sujeito de verbos de emoção & Recipiente \\
\hline
\end{tabular}

Quadro 9: Correlação entre sujeito, objeto e classes de verbos (Revisado)

\subsection{A ordem dos constituintes na estrutura sintática}

Estamos considerando aqui apenas o verbo e os constituintes necessários à gramaticalidade da sentença. A estrutura informacional pode vir a ser bastante diferente, mas não estaremos enfrentando essa questão neste ponto.

A ordem dos argumentos na estrutura gramatical do Ofayé é bastante fluida. Andrews (1985, p. 71) observa que tem-se encontrado "[...] systems in which there is a preferred order, but

Esta estratégia de marcação do argumento central sujeito como um caso oblíquo nāo é, contudo, propriamente exótica. Muitas línguas seguem um padrão comum, Ergativo-absolutivo, Nominativo-acusativo, Ativo-estativo, para as demais classes de verbos, mas sentenças com verbos de percepção, emoçāo, cogniçāo, seguem um padrāo diferente. Entre essas línguas, incluem-se linguas bem conhecidas, como Alemāo, Espanhol c Croata (VAN VALIN, 2001, p. 27-28). 
where a great deal of variation is possible as long as ambiguity is not introduced (though some languages seem to tolerate surprising amounts of ambiguity)". Um exemplo de uma língua desse tipo, segundo Andrews, é Dakota, cuja sintaxe

[‥] does not seem to be sensible to try to describe the order possibilities in terms of a basic order and specific alternatives. Rather, the order is free, subject to a sov preference, especially when needed to prevent ambiguity. This sort of system we will call 'fluid', as opposed to the high determinate word-order system of languages like English (ANDREWS, 1985, p. 72).

A ordem dos constituintes gramaticais na estrutura sentencial em Ofayé é, como vimos demonstrando, SOV. Essa parece ser uma ordem de constituintes bastante típica em línguas do tronco Macro-Jê.

\subsubsection{A ordem na estrutura intransitiva ativa}

Na estrutura intransitiva ativa, a ordem básica é SV. O sujeito é sempre representado por um pronome da classe ativa, /ta/, /te/, / õta/, primeira, segunda e terceira pessoa, respectivamente. O sujeito de terceira pessoa poderá correferenciar a um nominal. Nesse caso, a ordem do nominal é bastante fluida. Ele poderá vir:

20) [ [ fo õtว hoge]

afo õto hoge-ge

menino 3SUJ gritar-VER

o menino gritou 
b) depois do pronome

21) [õta əfo hoge]

õta afo hoge-ge

3SUJ menino gritar-VER

o menino gritou

c) depois do verbo

22) [õta hoge ifo]

õta hoge-ge afo

3SUJ gritar-VER menino

o menino gritou

Uma observação a se fazer é que esta última parece ser a ordem canônica. É a que mais freqüientemente é fornecida em dados elicitados.

\subsubsection{A ordem na estrutura transitiva}

$\mathrm{Na}$ estrutura transitiva, a ordem dos constituintes pronominais é SOV.

23) [ta ã ki ]

ta ã gi

1SUJ 3OBJ ver

eu o vejo/vi

Se os pronomes gramaticais correferenciarem a nomes abertos na sentença, a ordem desses nominais pode ser variada. 
1) um nominal é correferenciado por /o)t"/ terceira pessoa de verbos ativos, e o objeto é também expresso nominalmente. Como nos verbos intransitivos, o nominal sujeito pode vir:

correferencia

a) na primeira posição da sentença, antes do pronome que o

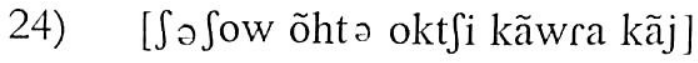

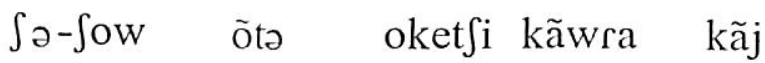

1POS-pai 3SUJ onça pintada matar

meu pai matou a onça pintada

b) depois do pronome correferenciador

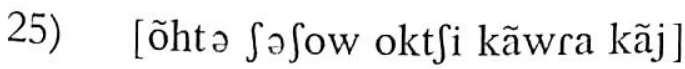

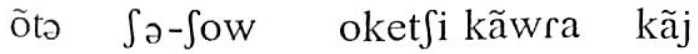

3SUJ 1POS-pai onça pintada matar

meu pai matou a onça pintada

c) depois do verbo, ou seja, ocupando a última posição na sentença

26) [õtə $\mathrm{f}^{\mathrm{w}}$ inwegi wej $\left.\int \partial \int \mathrm{Sow}\right]$

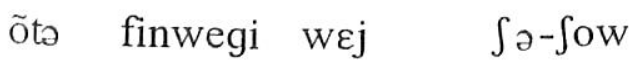

3SUJ pote quebrar 1POS-pai

meu pai quebrou o pote

No último exemplo, o nominal [ $\left.\int \curvearrowright \int o w\right]$ meu pai, ocupa a última posição na sentença. O objeto direto [ $\mathrm{f}^{\mathrm{w}}$ inwegi] pote mantém a sua posição imediatamente antes do verbo ${ }^{6}$ [wej] quebrar.

Lembremo-nos que, quando o objeto näo é expresso por um nome, a posição imediatamente anterior ao verbo é preenchida pelo pronome objeto. 
Há, ainda, uma outra ordem, com todos os nominais ocorrendo depois do verbo, espelhando os pronomes correferenciadores. O pronome sujeito /õta ', que é obrigatório, vai estar sempre por perto do nome que ele correferencia, exceto nessa terceira ordem.

2) o sujeito é expresso pronominalmente, desde que primeira pessoa. O objeto de terceira pessoa é expresso nominalmente e não é correferenciado por um pronome.

27) [ta f $\mathrm{f}^{\mathrm{w}}$ inwegi wej]

ta finwegi wej

1SUJ pote quebrar

nós quebramos o pote

A ordem é SVO. Note-se, porém, que podemos sempre considerar que o pronome para objeto de terceira pessoa pode ser [ø], o que acontece em outros tipos de estrutura. Assim, diríamos que [ $\mathrm{f}^{\mathrm{w}}$ inwegi] estaria sendo correferenciado por este elemento [ø] antes do verbo. Se o objeto expresso nominalmente ocupar a posição comum ao objeto, a ordem SOV será mantida.

\subsubsection{A ordem na estrutura bitransitiva}

$\mathrm{Na}$ estrutura bitransitiva, com três papéis semânticos principais correspondendo aos três argumentos centrais, a ordem é, se esses argumentos são expressos pronominalmente, S-OI-OD-V. Se alguns desses constituintes forem expressos por nomes, há variações nessa ordem. A ordem em Ofayé é extremamente fluida, e é possível encontrar-se essa fluidez nos dados que vimos descrevendo, como, por exemplo, na descrição da estrutura bitransitiva. Por isso, deter-nos-emos nesta secção apenas no que nos parece ser a ordem mais básica, embora nem sempre a que mais transparece na fala fluida. 
a) todos os constituintes são expressos pronominalmente, menos, obviamente, no exemplo abaixo, o sujeito, porque ele é de terceira pessoa e o recipiente é de primeira pessoa.

28) [ a he ã nõ]

ø wa he hã nãw

3SUJ 1OBJ DAT 3OBJ dar

ele me deu (algo)

b) todos os constituintes, desde que de terceira pessoa, são expressos nominalmente. A estrutura básica apresentar-se-ia como no exemplo a seguir.

29) [ok ${ }^{\mathrm{w}} \mathrm{ie}$ õta he nõ maria he krigete]

ok ${ }^{w i e}$ õtə ø he nãw maria he garigete Okwin 3SUJ 3OBJ DAT dar Maria DAT ovo Ioana deu o ovo a Maria

Nessa estrutura, que estamos propondo como sendo a estrutura mais básica em que aparecem todos os constituintes da sentença gramatical em Ofayé, a ordem é Sujeito (Pron)-Objeto Indireto (Pron)-Objeto Direto (N)-V-Objeto Indireto (N)-Objeto Direto $(N)$, na qual os constituintes gramaticais têm a sua referência explicitada depois do verbo por um sintagma nominal. Para que o recipiente seja distinguido do tema - o objeto transferido - o nome referente ao recipiente é, do mesmo modo que o pronominal [ø] antes do verbo, marcado como Dativo.

\subsubsection{A ordem na estrutura estativa}

Na estrutura estativa, a ordem é SV, quando o sujeito é expresso apenas pelo pronome. Se o sujeito for explicitado por um 
nominal, a ordem desse nominal é igual à que ocorre na estrutura intransitiva, acima descrita.

30) [ã grej]

ã garej

3SUJ bom

é bom

31) [ã grej əfo]

ã garej əfo

3SUJ bom menino

o menino é bom

3.1.5 A ordem na estrutura com verbos de emoção

$\mathrm{Na}$ estrutura com verbos de emoção, a ordem é SOV, se o objeto for expresso apenas pelo pronome.

32) $[a$ he Sẽfi]

a he Jẽti

1OBJ DAT gostar

eu gosto dele

Se explicitado por um nome, que tem referência plena, o objeto pode vir antes ou depois do verbo. A ordem mais freqüente é, porém, com o nome que refere ao objeto depois do verbo.

33) [a he Jẽfi Sagije]

a he Jẽti So-gije

1OBJ DAT gostar 1POS-marido

eu gosto do meu marido 


\section{Conclusão}

Neste artigo, apresentamos uma breve descrição da estrutura sintática do Ofayé. De acordo com a descrição efetuada, podemos considerar que a língua apresenta características de línguas com estrutura Ativa/Estativa. O modo como os pronomes são usados, porém, dizemos que a língua apresenta uma intransitividade cindida, dado que os verbos intransitivos são divididos em duas classes, uma que se comporta do mesmo modo que os verbos transitivos primários e outra que recebe outro tipo de sujeito. Ao lado dessa estrutura predominante, há algumas construções marginais, como, por exemplo, a construção com verbos de emoção e de cognição, que apresentam um sujeito marcado como Dativo e, portanto, com papel semântico Recipiente, na estrutura sintática.

\section{Abreviaturas}

1 Primeira Pessoa

2 Segunda Pessoa

3 Terceira Pessoa

DAT Dativo
OBJ

POS

SUJ

VER
Objeto

Possessivo

Sujeito

Verbalizador

\section{Referências}

ANDERSON, S. R. Typological distinctions in word formation. In SHOPEN, T. (ed.) Language typology and syntactic description. Vol. III Gramamatical categories and the lexicon. Cambridge: Cambridge University Press, 1985. 
ANDREWS, A. The maior functions of the noun phrase. In: SHOPEN, T. (ed.) Language typology and description. Vol. I Clause and structure. Cambridge: Cambridge University Press, 1985.

DIXON, R. M. W. Subject and object in universal grammar. In: ARNOLD, D. et al. (eds.). Essays on grammatical theory and universal grammar. Oxford: Clarendon Press, 1990. p. 91-118.

DUTRA. C. A. S. Ofaié: morte e vida de um povo. Campo Grande: Instituto Histórico e Geográfico de Mato Grosso do Sul, 1996.

GIVÓN, Talmy. Functionalism and grammar. Amsterdam: John Benjamins, 1995.

John Benjamins, 1997.

(ed.) Grammatical relations. A functionalist perspective. Amsterdam:

- Syntax. A functional-typological introduction. Vol. I e II. Amsterdam/Philadelphia: John Benjamins, 1990.

RODRIGUES, A. D. Línguas brasileiras. Para o conhecimento das línguas indígenas. São Paulo: Loyola, 1986.

VAN VALIN, Robert D. Jr. \& LAPOLLA, Randy J. Syntax. Structure, meaning and function. Cambridge: CUP, 1997.

. Grammatical relations in ergative languages. Studies in Language 5(3), p. 361-394, 1981. 